otherwise normally coloured, are inherited as typical Mendelian dominants, the affection being always transmitted in the direct line. On the other hand, many, probably the majority, of cases of complete or nearly complete albinism behave as recessives, and appear especially in the offspring of consanguineous marriages between affected stocks.

When the more sharply defined cases have been separated out, there remains a large mass of material which still requires analysis, and one of the most hopeful ways of dealing with this seems to be by a comparison with cases in animals which have been or might be worked out experimentally. Such experiment has already shown, first, that skin and coat colour is due to the combined effect of at least two separately inherited factors, one of which is necessary for the production of any kind of pigment, while the other determines the colour of the pigment which is produced. Vertebrate albinos are commonly produced by the absence of the first factor, and may therefore bear the factors which determine particular colours, although they do not show them. Albinos are therefore not all alike in their inherited constitution, and it is probably only by disentangling the various factors involved that a complete understanding of the causes of human albinism will be obtained. Secondly, experiment with animals shows that piebalding is completely distinct from total albinism in its inheritance, and that if a piebald appears when an albino is crossed with a self-colour, this is not due to mosaic inheritance, but to the fact that the albino bears the factor for piebalding-is, in fact, a piebald from which the pigment factor is lacking. Thirdly, there is evidence that some cases of lack of pigment are due to an inhibiting factor which interferes with the development of pigment, even in the presence of both the required colour-factors. When complications of this kind have been shown to exist in animals which can be subjected to rigorously controlled experiment, it is not surprising that the examination of human albinos and their pedigrees reveals irregularities.

A comparison with animal cases suggests, however, that by the careful collection of evidence, and especially by the classification of cases (I) according to the results of clinical observation, supplemented by microscopical examination when possible, and (2) according to the mode of inheritance, much could be done to disentangle the various factors which are involved. Much of the preliminary work in this direction could be done with the data now available, but as long as we continue to group together, in thought as well as in name, such different phenomena as total absence of pigment, general reduction of pigment, piebalding, and wall-eye, and, from the point of view of inheritance, cases which are clear Mendelian dominants, others which are scarcely less clearly recessive, and others, again, which have undoubted sex-limited inheritance, so long the present confusion will continue.

The monograph before us, though scarcely making any attempt at a classification such as we suggest, will provide most useful material for future workers on the subject. It gives a full account of the clinical and microscopic characters of various kinds of albinism in the widest sense of the word, both in man and animals; discusses their occurrence and geographical distribution, and includes, in part iv., nearly 7oo fully described pedigrees, some of them extending to roo or more individuals.

\section{PROF. S. P. LANGLEY AND AVIATION.}

I have brought to a close the portion of the work which seemed to be specially mine, the demonstration of the practicability of mechanical flight; and for the next stage, which is the commercial and practical development of the idea, it is probable that the world may look to others. The world, indeed, will be supine if it do not realise that a new possibility has come to it, and that the great universal highway overhead is now soon to be opened.

THUS spoke the late secretary of the Smithsonian Institution, Samuel Pierpont Langley, after his memorable experiment of May 6, 1896, in which he launched a heavier-than-air machine in the air, which flew under its own power (steam), traversing a distance of half a mile. This experiment it was that convinced the world of the practicability of mechanical flight, and which crowned the success of all his previous experimental researches. It was not until the year 1903 (December I7) that the Brothers Wright, Wilbur and Orville, fitted a motor to their gliding machine, and made two flights, the first successful flights ever made by man in a heavier-than-air machine driven by its own power.

It was a fitting tribute of the Board of Regents of the Smithsonian Institution to found, on December I5, I908, a Langley medal "to be awarded for specially meritorious investigations in connection with the science of aerodromics and its application to aviation," and it was most appropriate that the brothers Wilbur and Orville Wright were the first (I909) to receive the award. The presentation of this medal is now made on May 6, a date selected in order that the ceremonies incident to the presentation may take place in connection with the observance of "Langley Day," which was established by the Aero Club of Washington in I9I I to commemorate Langley's achievement.

A recent Smithsonian Institution publication (No. 2233) contains an account of the exercises on the occasion of the presentation of the Langley Medal and the unveiling of the Langley Memorial Tablet on May 6, I9I3, including the addresses of Dr. Alexander Graham Bell, Monsieur J. J. Jusserand, the Ambassador to the United States, Dr. John A. Brashear, and the secretary, Dr. Charles D. Walcott. The bronze memorial tablet is situated in the Smithsonian building, and represents Prof. Langley seated on a terrace where he has a clear view of the heavens, and, in a meditative mood, is observing the flight of birds, while in his mind he sees his aerodrome soaring above them.

NO. 23 I3, VOL. 92] 
The second and third medals were awarded to Mr. Glen H. Curtiss and M. Gustave Eiffel, the former "for advancing the art of aerodromics by his successful development of a hydro-aerodrome, whereby the safety of the aviator has been greatly enhanced," and the latter "for advancing the science of aerodromics by his researches relating to the resistance of the air in connection with aviation."

The orations are interesting reading, especially that by Dr. Brashear, who was one of Prof. Langley's oldest and closest friends.

The publication contains reproductions of the Langley Tablet and of the two handsome medals. The illustration of the medal awarded to M. Eiffel is here reproduced.

At the close of the exercises, the secretary directed attention to the action of the Board of Regents, who have decided on the re-opening of the Langley Aerodynamical Laboratory. Suffi- out from the Eiffel Tower. Protests against the proposed tax had been forwarded to the Post Office authorities by the National Association of Goldsmiths, the British Horological Institute, and Mr. F. HopeJones, chairman of the Wireless Society of London. In consequence of the representations made to it upon the subject, an inquiry was instituted by the British Science Guild in relation to the wisdom of the policy of levying such a charge at the present time, the possibility of collecting the same economically in the event of the policy being persisted in, as well as in relation to the powers conferred on the Postmaster-General under the Wireless Telegraphy Act, I904. The result of this inquiry was such as to persuade the guild that the imposition of a tax would be impolitic, and at the same time would not be likely to produce a revenue commensurate with the expense involved in attempting to collect the same, whilst such a tax could not fail to give rise to intense irrita-

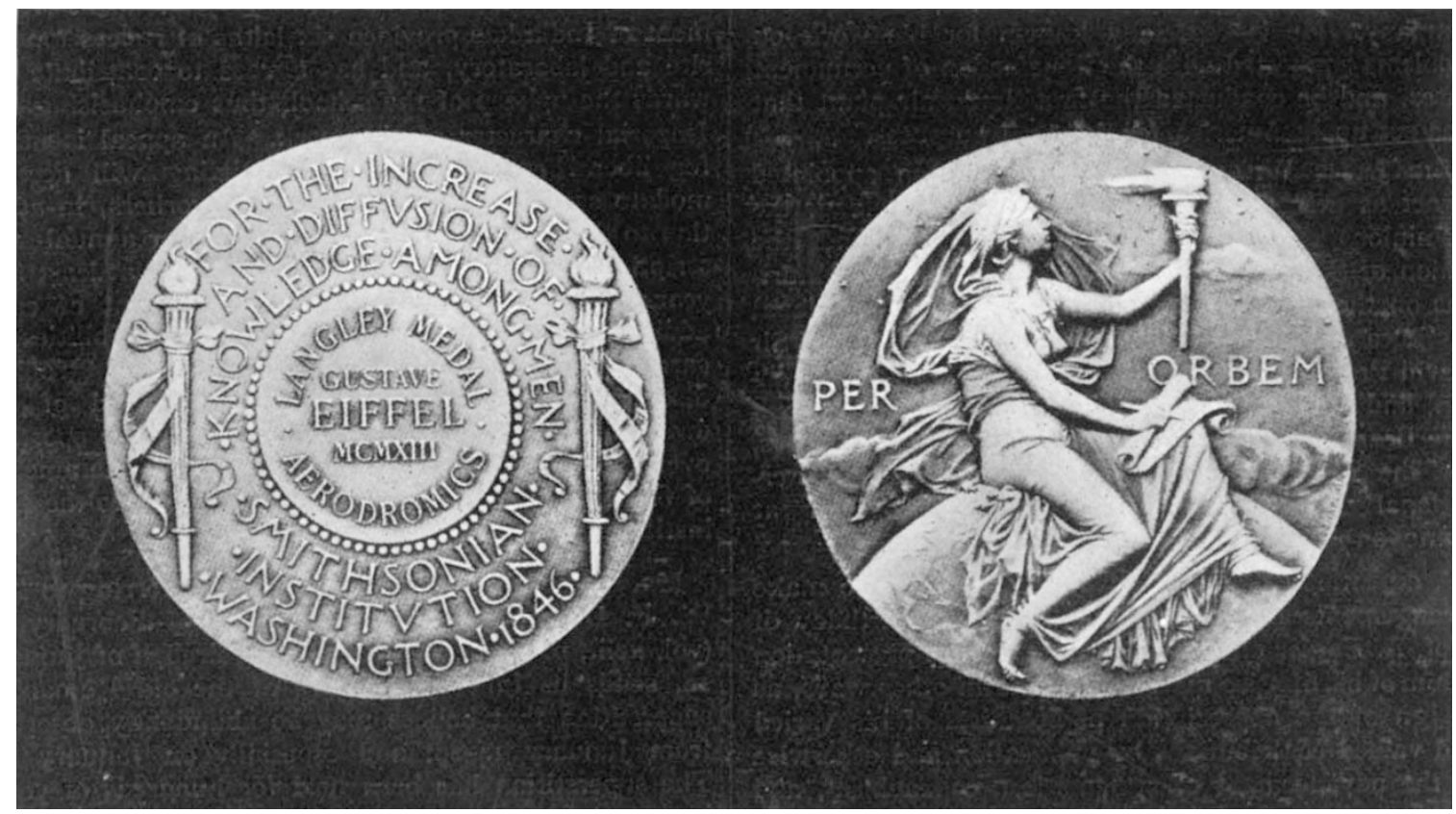

FIG. r.-Langley medal presented to M. Gnstave Eiffel.

cient provision is available to start and continue the work in a modest way, and it is hoped that investigations under the name of Langley will be pursued to develop and standardise aeronautical science.

Such an institution well organised and equipped would be a noble monument to the man, and one which he, no doubt, would have most desired.

\section{NOTES.}

THE attention of the British Science Guild was directed towards the end of last year to the fact that the Post Office authorities were contemplating a charge of two guineas; in respect of licences in connection with apparatus proposed to be installed by owners of observatories, watch and clock makers, \&c., for the purpose of receiving the international wireless time signals sent tion. As was pointed out in an article in NATURE of November I3, I9I3 (p. 320), it appeared to be extremely doubtful whether the Postmaster-General possessed statutory authority to impose such a tax, since by the terms of the Wireless Telegraphy Act, I904, it is expressly provided that "nothing in this Act shall prevent any person from making or using electrical apparatus for any purpose other than the transmission of messages." The views of the British Science Guild were recently forwarded to the Secretary of the Post Office, who was desired to place the document containing these views before the PostmasterGeneral for his consideration, and at the same time the Postmaster-General was requested to receive a deputation from the guild in relation to this matter. We learn that the representations of the British Science Guild and other bodies have been considered by the Postmaster-General, who has now intimated NO. 2313 , VOL. 92] 